\title{
Effect of Ipratropium Inhalation on Pupil Dilatation in Rats
}

\author{
(1) Hatice Șeyma Akça, (1) Büșra İhtiyar, (1) Kamil Kokulu, (1) Abdullah Algın, (1) Serdar Özdemir, (1) Serkan Emre Eroğlu, \\ (D) Gökhan Aksel
}

Department of Emergency Medicine, University of Health Sciences Turkey, Ümraniye Training and Research Hospital, İstanbul, Turkey

\begin{abstract}
Aim: This study aimed to investigate the effect of inhaled ipratropium on pupil diameter when applied directly to the eye in a closed environment.

Materials and Methods: A total of 14, 8-week-old and 350-g weight Sprague-Dawley rats were obtained from Yeditepe University Laboratory of Experimental Animals for research. At constant temperature $\left(22^{\circ} \mathrm{C} \pm 3^{\circ} \mathrm{C}\right)$ and 12 -hour light/dark cycle, the rats had access to standard food and water. A total of 7 rats were exposed to ipratropium, whereas 7 rats were given saline nebular. Pupil diameters and pupillary-orbital diameter ratios were compared before and 2 hours after drug exposure.

Pupil diameters and pupillary-orbital diameter ratios measured before and 2 hours after ipratropium inhalation were compared in the computer environment after $4288 \times 2848$ pixel magnification.

Results: No significant difference was observed in the pupil/orbital diameter ratios in either right or left eyes after treatment compared to baseline values ( $p>0.05$, for both). No significant difference was found in Delta rates. The numerical data fitted the normal distribution.

Conclusion: In our study, no significant difference was determined in diameter changes that would advocate a more careful action in the case of anisocoria development in patients receiving ipropropium treatment and perform a detailed neurological examination and request neurology consultation as soon as possible. Anisocoria or changes in pupil diameters encountered in both pupils may not always be associated with drug use.
\end{abstract}

Keywords: Pupil diameter, nebulized ipratropium, anisocoria

\section{Introduction}

Obstructive pulmonary diseases are important health problems in our country and all over the world. Besides the preventive measures, it is necessary to know the mechanism of action and side effects of the drugs used. Asthma is a reversible chronic inflammatory disease of the respiratory tract resulting from increased bronchial hypersensitivity. Although inhalation beta-2 agonists and systemic corticosteroids are used in treatment, it has been reported that beta-2 agonists and inhalation quarternary ammonium derivative ipratropium bromide and atropine can also be used (1,2). Chronic obstructive pulmonary disease (COPD) is characterized by chronic inflammation in the airways, diffuse alveolar damage, and airway collapse and increase in respiratory work resulting from the loss of elasticity. Beta agonists and anticholinergic drugs are used during attacks. Due to their lipophilic quarternary ammonium structure, systemic absorption and toxicity in the inhalation use are lower in anticholinergics than in beta 2 agonists. The main mechanism of action of anticholinergic drugs such as ipratropium, oxitropium and tiotropium bromide is the blockade of the acetylcholine effect via $M_{3}$ receptors on airways in COPD patients (3).

The $\mathrm{M}_{3}$ receptor is the major mediator of the muscarinic receptors in bronchoconstriction, mucus secretion and mucociliary clearance. $\mathrm{M}_{3}$ stimulation activates phospholipase which causes an increase in inositoltriphosphate $\left(\mathrm{IP}_{3}\right)$ and intracellular calcium. 
Ipratropium is a non-selective antimuscarinic agent. However, in acute asthma, Ipratropium is more effective on the bronchi than other antimuscarinics. Antimuscarinics have a low oral absorption and they cannot cross the blood brain barrier (4).

Retinal vascularity lacks sympathetic innervation. Circulating hormones and local factors are the main determinants of retinal blood flow. Activation of central nervous system increases the level of circulating adrenaline and stimulates beta receptors in the retinal arterioles by increasing retinal blood flow (5). In obstructive airway diseases, inhaled ipratropium can block muscarinic receptors and cause pupil dilatation with local parasympatholytic effect $(6,7)$.

Mydriasis, cycloplegia, blur in vision, dryness in eyes may be observed due to local absorption of ipropropium. Unilateral or bilateral mydriasis has been reported due to leakage or due to improper placement of direct contact or face mask $(8,9)$.

In vivo studies have shown that beta 1, 2, 3 specific receptor agonists as well as beta agonists are effective in retinal vasodilatation. In these studies, the intravenous form of drug was used (10-13).

Clinical studies were carried out in the Emergency Medicine clinic of the University of Health Sciences Turkey, Ümraniye Training and Research Hospital, İstanbul. Except for clinical trials and case reports, there was no study to determine whether experimentally inhaled ipratropium had any effect on pupil dilation.

\section{Aim}

The aim of this study was to investigate the effect of inhaled ipratropium on pupil diameter when applied directly onto the eye in a closed environment.

\section{Materials and Methods}

A total of 14, 8-week-old and 350-g weight Sprague dawley rats were obtained from Yeditepe University Faculty of Medicine Experimental Research Center. At constant temperature $\left(22 \pm 3^{\circ} \mathrm{C}\right)$ and 12-hour light/dark cycle, the rats had access to standard feed and water. Seven rats were exposed to ipratropium while seven rats were given saline nebular. Pupil diameters and pupillaryorbital diameter ratios were compared before exposure and 2 hours after exposure to the drug.

In a closed environment, ipratropium nebular was inhaled at a dose of $1.5 \mathrm{mg} / \mathrm{kg}$. The control group received the same dose of saline inhalation. The use of masks was not possible in rats. There was no mask for the rats. Ipratropium was given with the help of nebulizer in the closed area covered with glass, which the rats could easily move, we could observe from the outside.
Thus, direct eye contact was achieved. Saline administration to the control group was performed with the same method. The rat pupil diameters were measured using original highresolution nikon digital fundus camera $(1.5 \mathrm{ft}, 0.45 \mathrm{~mm})$ at the same temperature $\left(22 \pm 3^{\circ} \mathrm{C}\right)$ and lightened environment. Photos were obtained and recorded in the same heat and light environment at a $90^{\circ}$ angle at a distance of $30 \mathrm{~cm}$ to the orbit. Pupil diameters and pupillary-orbital diameter ratios measured before and 2 hours after inhalation ipratropium administration were compared in the computer environment after $4288 \times 2848$ pixel magnification. The same method was applied for the control group.

\section{Statistical Analysis}

Collected data analysis was performed by using SPSS software (version 20.0, SPSS Inc., Chicago, Illinois). The Shapiro-Wilk test was used to evaluate distribution of continuous variables. Normally distributed continuous variables were compared with Student's t-test, while non-normal distributed continuous variables were compared with Mann-Whitney $U$ test. Pupil diameters of rats before and second hours were compared with paired t-test and/or Wilcoxon tests. The results were evaluated at $95 \%$ confidence interval and a $p$-value of $<0.05$ was considered as statistically significant.

Ethics committee was given by Yeditepe Experimental Research Center where the study was conducted. No treatment was applied to the subject rats after drug exposure.

\section{Results}

There were also significant differences in the pupil diameters of the rats at the $0^{\text {th }}$ hour measurements. For this reason, we thought that we would get reliable results with the ratio of pupil diameter/orbital diameter and delta value.

An increase in the mean right pupil diameter was observed at the $2^{\text {nd }}$ hour compared to the baseline in the ipratropium group, but this difference was not statistically significant $(p=0.09)$. Although there was an increase in left pupil diameter, no statistically significant difference was found $(p=0.05)$. There was no significant difference in pupil diameter ratios in either the right or the left eyes after treatment compared to baseline values ( $p>0.05$, for both). There was a significant difference in pupil/ orbital ratio in right $(p=0.014)$ and left $(p=0.016)$ eye, but not in delta values. Madication and Control Group Pupil Diameter, Orbital Diameter and Delta Ratios are specified in the table (Table 1).

There was no significant difference in Delta rates (right pupil $p=0.67$, left pupil $p=0.95$ ). The numerical data fitted the normal distribution. 


\begin{tabular}{|c|c|c|c|}
\hline Data & Iratropium group & Control group & $\mathrm{p}$ \\
\hline Right pupil $0^{\text {th }}$ hour average diameter (pixel) & $7.0 \pm 1.7$ & $5.5 \pm 1$ & 0.07 \\
\hline Left pupil $0^{\text {th }}$ hour average diameter (pixel) & $7 \pm 1.7$ & $5.5 \pm 1$ & 0.07 \\
\hline Left pupil/left orbit 0 hours (\%) & $16.4 \pm 3.6$ & $12 \pm 2.3$ & 0.017 \\
\hline Right pupil/right orbita $2^{\text {nd }}$ hour (\%) & $17.2 \pm 2.6$ & $13 \pm 2.7$ & 0.014 \\
\hline Left pupil $2^{\text {nd }}$ hour averagediameter (pixel) & $7.8 \pm 1.8$ & $5.8 \pm 1.4$ & 0.05 \\
\hline Left pupil/left orbita $2^{\text {nd }}$ hour (\%) & $16.8 \pm 3.2$ & $12.4 \pm 2.5$ & 0.016 \\
\hline Delta right pupil & $0.5 \pm 3.5$ & $1.1 \pm 1.6$ & 0.67 \\
\hline
\end{tabular}

\section{Discussion}

Anticholinergic drugs are more effective in COPD than in asthma (3). The significant side effects of inhaled anticholinergics are mouth dryness and cough. Metallic taste and urinary obstruction may occur rarely. Headache, nervousness, irritability, dizziness, nausea, constipation, tachycardia and rashes can also be seen. Paradoxical bronchospasm may occur due to the preservative ingredients in the nebulizer ipratropium (2,3,14-16).

Only $1 \%$ of ipropathium is absorbed; therefore, it has a wide therapeutic range. There are different reportsregarding the effect initiation time and maximum duration of effect in different papers. According to some authors, the bronchodilator effect starts at 30 to 120 minutes, lasts for 4-8 hours, and the half-life is 3.2 hours $(2,17-19)$.

According to some reports, the aerosol reaches its maximum effect after 30-60 minutes of application and its effect lasts for 3-6 hours (20-25).

The most technically feasible inhalation doses of metered dose aerosol are $1.5 \mathrm{mg} / \mathrm{kg} /$ day in rats and $1.8 \mathrm{mg} / \mathrm{kg} /$ day in rabbits. There was no adverse effect on the reproductive system. Ipratropium bromide solution in water $(0.05 \mathrm{mg} / \mathrm{kg})$ was locally well tolerated when administered to rats by inhalation (single administration for 4 hours). In repeated dose toxicity studies, ipratropium bromide was locally well tolerated (26).

In our study, ipratropium was given at a dose of $1.5 \mathrm{mg} / \mathrm{kg} /$ day. No rat died during or after the procedure. Decapitation was not performed in rats; there was no change in pupillary diameter or the ratio and no other side effects were observed either. Two hours after drug administration, the pupil diameter and the pupil diameter/orbital diameter ratios and delta values were measured and evaluated. As the size of the orbital diameters may vary slightly, the ratio of the pupil diameter to the orbital diameter was also included in our data. Although large-scale studies are not sufficient, there is no in vivo study comparing the changes in pupil diameter after inhaled ipratropium. Inhaled ipratropium contact with the eye in aerosol form may sometimes present with mydriasis and sometimes anisocoria. This may be due to mask mismatch, patient discordance, or mask shape. Mydriasis due to aerosol leakage has been reported in cases receiving ipratropium treatment. These cases were mostly published as case reports. The normal mental status and absence of any speech disorder or hemiparesis has led to exclusion of a possible herniation diagnosis (25-30).

To date, there is an insufficient number of clinical studies on the effect of inhaled ipratropium on pupil dilatation. In the case reports, it was emphasized that the patients receiving ipratropium treatment could experience anisocoria or change in pupildiameters in both pupils, and therefore, unnecessary examination should be avoided.

In our study, no significant difference in diameter changes were determined that would advocate that we should be more careful in the case of anisocoria development in patients receiving ipropropium treatment and to perform a detailed neurological examination and request neurology consultation as soon as possible. Anisocoria or changes in pupil diameters that we may encounter in both pupils may not always be associated with drug use.

\section{Conclusion}

Our study is important in terms of demonstrating that significant pupil dilatation does not occur due to ipratropium inhalation in rats. 
In addition to clinical studies, it is necessary to conduct largescale experimental animal studies and detailed studies for longterm side effects.

\section{Ethics}

Ethics Committee Approval: Ethics committee was given by Yeditepe Experimental Research Center where the study was conducted (decision no: 693, date: 19.09.2018). No treatment was applied to the subject rats after drug exposure.

Informed Consent: It was obtained.

Peer-review: Externally peer-reviewed.

\section{Authorship Contributions}

Surgical and Medical Practices: H.Ş.A., S.E.E., S.Ö., B.İ., Concept: S.E.E., A.A., G.A., Design: H.S.A., S.Ö., K.K., A.A., Data Collection or Processing: H.Ș.A., B.İ., S.E.E., G.A., Analysis or Interpretation: B.I.., G.A., K.K., A.A., Literature Search: H.Ș.A., S.E.E., S.Ö., B.I., Writing: H.Ş.A., K.K., B.I.

Conflict of Interest: No conflict of interest was declared by the authors.

Financial Disclosure: The authors declared that this study received no financial support.

\section{References}

1. Expert Panel Report 3(epr-3): Guidelines for the Diagnosisand Management of Asthma-SummaryReport 2007, National Asthma Education and Prevention Program, J Allergy Clin Immunol. 2008;121:1330.

2. Gökalp A S, Biçer S, Siraneci R. Efficacy of nebulize-pratropium bromide in the treatment of child hood acute asthma attack: double blind randomized controlled study, Nobel Medicus. 2013;9:67-75.

3. Çelik G, Kaya A, Çiledağ A. Bronchodilator therapy and supportive therapies in COPD, TTD Thorac Surg Bull. 2010;2:124-35.

4. Waller, DG, Sampson AP. Asthma and chronic obstructive pulmonary disease. Medical Pharmacology and Therapeutics, 5th ed. China: 2018.

5. Mori A, Higashi K, Wakao S, Sakamoto K, Ishii K, Nakahara T. Probucol prevents the attenuation of $\beta 2$-adrenoceptor-mediated vasodilation of retinal arterioles in diabetic rats, Naunyn-Schmiedeberg's Arch. Pharmacol. 2017;390:1247-53.

6. Kara N, Çelik S, Gürpınar G, Dalgıç N, Kafadar İ. Anisocoria in a Patient with Acute Bronchiolitis, J Pediatr Inf. 2018;12:32-4.

7. Penington K, Louis ES. "Don't believe your eyes" ipratropium induced mydriasis: a case report and review of the literature. Gen Med (Los Angeles). 2016;4:255

8. Vatansever \$, Kutluyurdu B, Sarı ME, Özyuvacı E. Ipratropium bromide induced acute Aanisocoria, İstanbul Med J. 2009;10;53-4.

9. Jannun DR, Mickel SF. Anisocoria and aerosolized anticholinergics. Chest. 1986;90:148-9.

10. Nakazawa T, Sato A, Mori A, Saito M, Sakamoto K, Nakahara T, et al. $\beta$-adrenoceptor-mediated vasodilation of retinal blood vessels is reduced in streptozotocin-induced diabetic rats, Vascular Pharmacol. 2008;2-3:77-83.
11. Mori A, Miwa T, Sakamoto K, Nakahara T, Ishii K. Pharmacological evidence for the presence of functional $\beta 3$ - adrenoceptors in rat retinal blood vessels. Naunyn-Schmiedeberg's Arch Pharmacol. 2010;382:119-26.

12. Mori $\mathrm{A}$, Nakahara $T$, Sakamoto $K$, Ishii $K$. Role of $\beta 3$ - adrenoceptors in regulation of retinal vascular tone in rats. Naunyn-Schmiedeberg's Arch Pharmacol. 2011:384:603-8.

13. Mori A, Sekito A, Sakamoto K, Ishii K, Nakahara T. Stimulation of $\beta 1$ - and $\beta 2$ adrenoceptors dilates retinal blood vessels in rats, Naunyn-Schmiedeberg's Arch Pharmacol. 2017;390:527-33.

14. Watson WTA, Shuckett EP, Becker AB, Simons FE. Effect of nebulized ipratropium bromide on intraoculer pressures in children. Chest. 1994:105:1439-41.

15. DagnoneA J, Parlow JL. Effects of inhaled albuterol and ipratropium bromide on autonomic control of the cardiovasculer system. Chest. 1997:111:1514-8.

16. Bryant DH. Nebulized ipratropium bromide in the treatment of acute asthma. Chest. 1985;88:24-9.

17. Zorc CC, Pusic MV, Ogborn CJ, Lebet R, Duggan AK. Ipratropium bromide added to asthma treatment in the pediatric emergency department. Pediatrics. 1999;103:748-52

18. Aaron SD. The use of ipratropium bromide for the management of acute asthma exacerbations in adults and children: a systemic review. J Asthma. 2001;38:521-30.

19. Gross NJ. Ipratropium bromide. N Eng J Med. 1988;319:486-94.

20. Chaundry P, Friedman DI, Yu W. Unilateral pupillary midriasis from nebulized ipatropium bromide: a false sign of brain herniation in the intensive care unit. Indian J Crit Care Med. 2014;18:176-7.

21. Montuschi P. Pharmacological treatment of chronic obstructive pulmonary disease. Int J Chron Obstruct Pulmon Dis. 2006;1:4:409-23.

22. De Saint Jean M, Bourcier T, Borderie V, Moldovan M, Touzeau O, Laroche L. Acute angle-closure glaucoma after treatment with ipatropium-bromide and salbutamol aerosols. J Fr Ophthalmol. 2000;23:603-5.

23. Ortiz Rambla J, Hidalgo Morra JJ, Gascon Ramon G, Navarro Arambudo B, Acute angle-closure glaucoma and ipatropium bromide. MedClin (Barc) 2005;124:795.

24. Fernandez-Barrientos Y, Jimenez-Santos M, Martinez-De-La-Casa JM, Mendez Hernandez C, Garcia-Feijoo J. Acute angle-closure glaucoma resulting from treatment with nebulised bronchodilatators, Arch Soc Esp Oftalmol. 2006;81:657-60.

25. Pejik R, KlaricB. Transient Anisocoria in a Patient Treated with Nebulized Ipratropium bromide, Americanjournal of Ophthalmology Case Rep. 2017:11-33.

26. Atrovent $500 \mathrm{mcg} / 2 \mathrm{ml}$ tek dozluk flakon inhalasyon solüsyonu Kısa Ürün Bilgisi. Available at: https://kub.ilacprospektusu.com/ilac/5205-atrovent500-mcg-2-ml-tek-dozluk-flakon-inhalasyon-solusyonu-kub (Accessed: 24. 03.2019).

27. Helprin GA, Clarke GM. Unilateral fixed dilated pupil associated with nebulised ipratropium bromide. Lancet. 1986;2:1469.

28. Bisquerra RA, Botz GH, Nates JL. Ipatropium-bromide-induced acute anisocoria in the intensive care setting due to ill-fitting face masks. Respir Care. 2005;50:1662-4.

29. Camkurt MA, Ay D, Akkucuk H, Ozcan H, Kunt MM. Pharmacologic unilateral mydriasis due to nebulized ipratropium bromide. Am J Emerg Med. 2011;29:576e5-576e6.

30. Kokulu K, Öner H, Özen C, Eroğlu SE, Altunok I, Akça HŞ. Pharmacologic anisocoria due to nebulized ipratropium bromide: A diagnostic challenge. Am J Emerg Med. 2019;37:1217.e3-1217.e4. 